\title{
Effect of Process Parameters on the Size and Shape of Nano- and Micrometric Zinc Oxide
}

\author{
Jolanta Pulit-Prociak, ${ }^{1, *}$ and Marcin Banach ${ }^{1}$ \\ ${ }^{1}$ Cracow University of Technology, Faculty of Chemical Engineering and Technology, \\ 24 Warszawska St., 31-155 Cracow, Poland \\ * Corresponding author: E-mail: jolantapulit@ indy.chemia.pk.edu.pl \\ Tel. +481262820 92, fax. +48126282035
}

Received: 13-01-2016

\begin{abstract}
The paper presents a method of obtaining zinc oxide nano- and microparticles. In these studies microwave reactor and laboratory pressure reactor were used. Since microwave radiation accelerates proceeding of reactions, this way was found to be an effective method in the process of obtaining nanocrystallines of zinc oxide. The size of prepared particles rarely exceeded $500 \mathrm{~nm}$.
\end{abstract}

Keywords: Zinc oxide, nanoparticles, green chemistry

\section{Introduction}

Metal oxides occurring in nanometric scale are characterized by more valuable properties comparing to the characteristics of the same macro-scale-materials. ${ }^{1}$ Such structures may be defined by ratio of surface area to their mass. This value is large enough so that other material properties are determined by surface properties. Due to their larger ratio of surface area to volume, they exhibit a higher chemical activity. ${ }^{2}$ Increased chemical activity of such materials may be explained by analyzing their structure. The size of the nanoparticles surface area increases significantly with decreasing their size. Small nanoparticle with a diameter of $1 \mathrm{~nm}$ has $100 \%$ of atoms disposed on its surface, while the particle with diameter of $10 \mathrm{~nm}$ has only $15 \%$ of surface atoms. Therefore, smaller particles are more chemically reactive. ${ }^{3}$

Zinc oxide is known primarily for its bleaching properties. It is used as inorganic pigment, ${ }^{4,5}$ catalyst $^{6,7}$ as well as sunglasses or wood coating material. ${ }^{8}$ Thanks to the fact that it is transparent for visible wavelength range of sunlight nanosized zinc oxide may be used as a blocker of harmful ultraviolet irradiation. ${ }^{9,10}$ In addition, zinc oxide nanoparticles have antibacterial and wound-healing properties. ${ }^{11,12}$ Thanks to their biocidal properties they found application for example in the production of antimicrobial textiles. ${ }^{13}$ Since zinc oxide has valuable electrical, optielectronic and photochemical properties, it has been also used in electrotechnique. ${ }^{14}$
There are many methods for the preparation of zinc oxide in the nanocrystalline form. Nawaz and colleagues have described a synthesizing of zinc nanooxide by wet chemical method using zinc nitrate, sodium hydroxide and starch which served as stabilizing agent. Obtained product exhibited antibacterial properties. ${ }^{15}$ Parashar synthesized nanometric zinc oxide by mixing an organic solution of a zinc precursor with an alcoholic base solution and adding acetone in order to precipitate a milky white zinc oxide. ${ }^{16}$ Nanometric zinc oxide may be also synthesized by metallurgical and mechanochemical processes, controlled precipitation method as well as by solgel, solvothermal and hydrothermal methods. ${ }^{17}$ Ohara and colleagues obtained highly crystalline zinc oxide nanoparticles by the way of supercritical water hydrothermal synthesis. $^{18}$

In this paper studies on obtaining zinc oxide nanoand microparticles in a field of microwave radiation and in the laboratory pressure reactor have been described. The aim of the work was to also compare the physicochemical properties of obtained products.

\section{Experimental}

\section{1. Materials}

Zinc nitrate hexahydrate $(\geq 99.0 \%)$ was used as zinc precursor. Sodium hydroxide $(\geq 98 \%)$ served as pre- 
cipitating substance. Both chemicals were obtained from Sigma Aldrich. Solutions were prepared in deionized water.

\section{2. Methods}

The first phase of studies was common for both types of processes. It concerned the precipitation of zinc hydroxide by adding an aqueous solution of sodium hydroxide to an aqueous solution of zinc nitrate. The process runs at room temperature under continuous stirring. Sodium hydroxide was used in a stoichiometric amount. Accurate amounts of raw materials used are presented in Table 1.

Table 1. Substrates used in the precipitation process

\begin{tabular}{lcc}
\hline Reagent & $\begin{array}{c}\text { Molar concentration, } \\
\mathbf{c}\left[\mathbf{m o l} / \mathbf{d m}^{3}\right]\end{array}$ & $\begin{array}{c}\text { Volume, } \\
\left.\text { V [ } \mathbf{c m}^{3}\right]\end{array}$ \\
\hline $\mathrm{Zn}(\mathrm{NO})_{3}$ & 0.1 & 25 \\
$\mathrm{NaOH}$ & 2.0 & 2.5 \\
\hline
\end{tabular}

In a further step, a dehydration process occurred. In order to accelerate that process, zinc hydroxide suspension was subjected to elevated temperature and pressure treatment. It was expected that the acceleration of dehydration process by applying elevated heat and pressure, promotes the formation of smaller crystallites of zinc oxide so that their size would be in the nanometric range. For this purpose, the suspension was transferred to a microwave reactor or laboratory pressure reactor.

\section{2. 1. Processes Carried Out in a Microwave Reactor}

The use of polar solvent (water) in the field of microwave radiation is possible to efficiently transfer the heat in a short time in the whole volume of the reaction mixture, which accelerates the process of dehydration. Dehydration processes carried out in a microwave reactor were varied directly through selection of different temperature-pressure conditions. In fact, these parameters were determined by specific values of microwave power and the residence time of the sample in the microwave field. Microwave power and residence time were independent parameters. They took three levels of volatility. The temperature and pressure values were read from plots generated in the program which assists the software dedicated to microwave reactor Magnum II from Ertec Poland. Process parameters are given in Table 2.

\section{2. 2. Processes Carried Out in a Laboratory Pressure Reactor}

Parameters of processes carried out in the laboratory pressure reactor (PARR 4525) were chosen arbitrarily, on the basis of preliminary studies. Their exact values are presented in Table 3.

Obtained suspensions were filtered on Buchner funnel using Whatman filters $(\mathrm{d}=0.45 \mu \mathrm{m})$ and washed with $160 \mathrm{~cm}^{3}$ of deionized water so as sodium nitrate would be removed. Solids were dried in air-dryer at $50{ }^{\circ} \mathrm{C}$ within 2 hours. Obtained products were analyzed by instrumental techniques. In the course of scanning electron microscopy a determination of the shape and indirect determination of

Table 2. Parameters of dehydration processes carried out in microwave reactor

\begin{tabular}{|c|c|c|c|c|c|c|}
\hline \multirow[b]{2}{*}{ Sample } & \multicolumn{2}{|c|}{ Input variables } & \multirow{2}{*}{$\begin{array}{c}\text { Temperature } \\
\text { achieved } \\
{\left[{ }^{\circ} \mathbf{C}\right]} \\
\end{array}$} & \multirow{2}{*}{$\begin{array}{c}\text { Pressure } \\
\text { achieved } \\
\text { [bar] }\end{array}$} & \multirow{2}{*}{$\begin{array}{c}\mathbf{d}_{\text {med }}[\mathbf{n m}] \\
\text { (based on } \\
\text { SEM) }\end{array}$} & \multirow{2}{*}{$\begin{array}{c}\mathbf{d}_{\text {med }}[\mathbf{n m}] \\
\text { (based on } \\
\text { Scherrer eq.) }\end{array}$} \\
\hline & $\begin{array}{c}\text { Microwave } \\
\text { power [\%] }\end{array}$ & $\begin{array}{l}\text { Residence } \\
\text { time [min] }\end{array}$ & & & & \\
\hline M1 & 70 & 3 & 100 & 9 & $20-200$ & 31 \\
\hline M2 & 70 & 5 & 160 & 15 & $10-200$ & 31 \\
\hline M3 & 70 & 7 & 200 & 26 & $20-200$ & 30 \\
\hline M4 & 85 & 3 & 100 & 11 & $50-300$ & 27 \\
\hline M5 & 85 & 5 & 180 & 25 & $100-200$ & 28 \\
\hline M6 & 85 & 7 & 230 & 39 & $40-250$ & 22 \\
\hline M7 & 100 & 3 & 110 & 14 & $40-200$ & 28 \\
\hline M8 & 100 & 5 & 200 & 39 & $80-200$ & 30 \\
\hline M9 & 100 & 7 & 240 & 39 & $60-250$ & 30 \\
\hline
\end{tabular}

Table 3. Parameters of dehydration processes carried out in laboratory pressure reactor

\begin{tabular}{lccccc}
\hline Sample & \multicolumn{2}{c}{$\begin{array}{c}\text { Input variables } \\
\text { Pemperature }\left[{ }^{\circ} \mathbf{C}\right]\end{array}$} & $\begin{array}{c}\text { Pressure achieved } \\
\text { Process time }[\mathbf{m i n}]\end{array}$ & $\begin{array}{c}\mathbf{d}_{\text {med }} \text { [nm] } \\
\text { (based on SEM) }\end{array}$ & $\begin{array}{c}\mathbf{d}_{\text {med }} \text { [nm] } \\
\text { (based on Scherrer eq.) }\end{array}$ \\
\hline R1 & 120 & 30 & 1 & $200-400$ & 32 \\
R2 & 160 & 30 & 4 & $50-400$ & 30 \\
R3 & 200 & 30 & 14 & $30-200$ & 30 \\
\hline
\end{tabular}



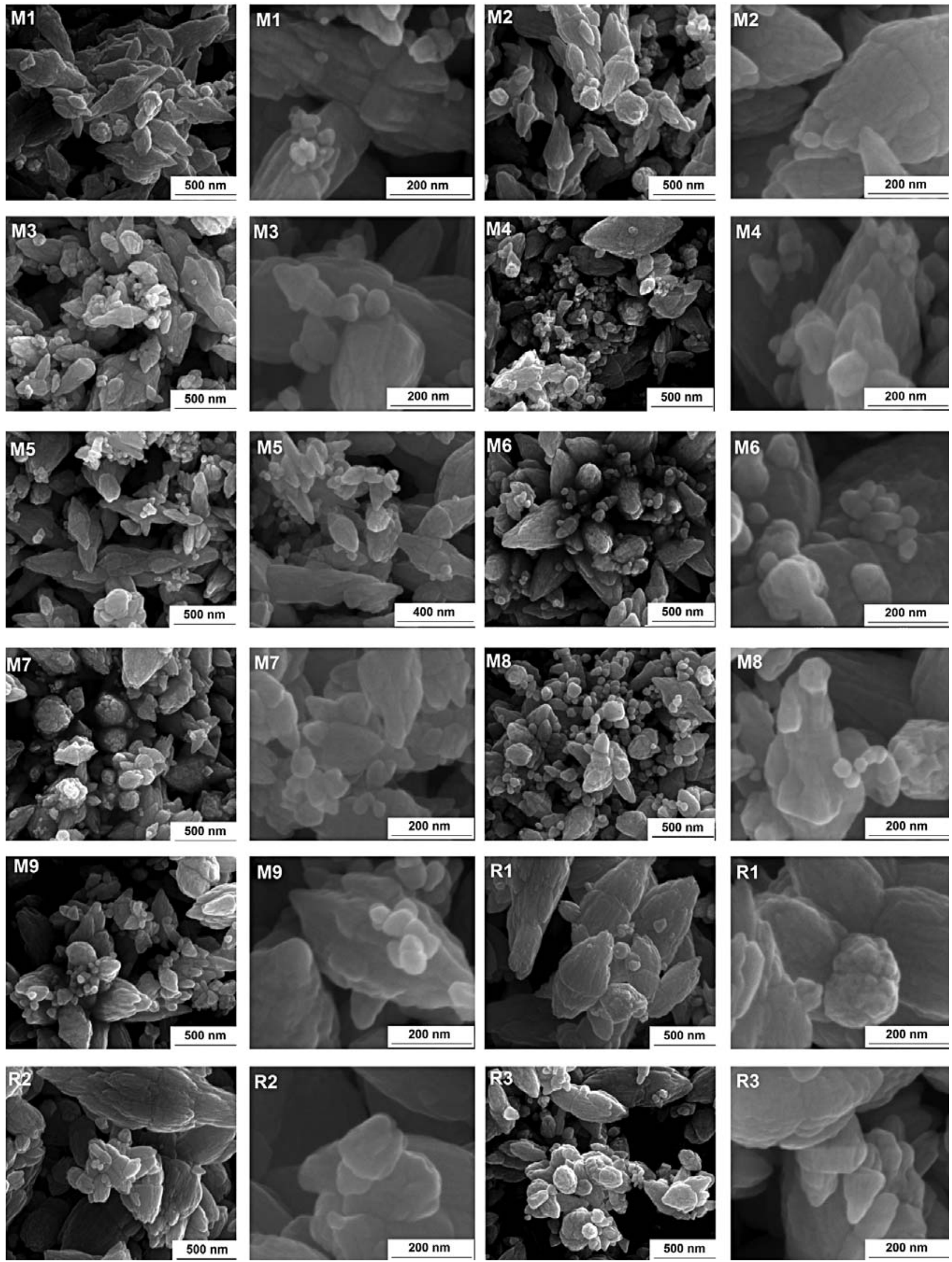

Fig. 1. Photomicrographs of obtained products 
zinc oxide particles size was possible. The study was carried out using 1430 VP microscope from LEO Electron Microscopy Ltd. In order to reveal the crystal structure, the sample was subjected to X-ray analysis conducted on X-ray diffractometer X'Pert PW 1752/00 from Philips. In order to detect vibrations characteristic of zinc oxide, samples were subjected to Fourier transform infrared spectroscopy. For this purpose spectrophotometer Nicolet 380 from Nicolet was used.

\section{Results and Discussion}

Preparation of zinc oxide proceeds according to the following equations:

$$
\begin{aligned}
& \mathrm{Zn}\left(\mathrm{NO}_{3}\right)_{2}+2 \mathrm{NaOH} \longrightarrow \mathrm{Zn}(\mathrm{OH})_{2}+2 \mathrm{NaNO}_{3} \\
& \mathrm{Zn}(\mathrm{OH})_{2} \stackrel{\Delta}{\longrightarrow} \mathrm{ZnO}+\mathrm{H}_{2} \mathrm{O}
\end{aligned}
$$

\section{1. Scanning Electron Microscopy}

Figure 1 presents SEM photomicrographs of obtained products.

The shape of obtained agglomerates may be defined as diverse and inhomogenous. It may be concluded that shape and size of particles depend on the conditions of their preparation. Comparing both reactors, it has been found out that the greater degree of variation in particles shape was reached when microwave reactor was used.
Despite a greater diversity of shape and size of products obtained in the microwave radiation field, the particles size was ranged from 10 to $300 \mathrm{~nm}$, while the particles obtained in the laboratory pressure reactor were larger their medium diameter was in the range from 30 to 400 $\mathrm{nm}$. Moreover, the influence of temperature on the minimum size difference between the largest and smallest particles is perceptible. Higher temperature determines lower size variation. It favours obtaining larger number of particles which are characterised by less diversified size. On the other hand, the mean particle size is dependent mostly on the dehydration time. When using microwave reactor, one may observe that initially the mean particles size decreases when residence time is elongated. After exceeding some time ( 5 minutes), the particles size slightly increases. This may be due to the fact that small particles form larger agglomerates which take place in final phase of the process. Products obtained in the course of hydrothermal synthesis within $5 \mathrm{~min}$ are characterized by physicochemical properties which are similar to properties of products obtained in a laboratory pressure reactor within 30 $\min$.

\section{2. X-ray Analysis}

Results of X-ray analysis are presented in Figure 2.

The resulting diffractogram indicates the receipt of zinc oxide. Peaks occurring in the area of $32^{\circ}, 34^{\circ}$ and $36^{\circ}$ of $2 \theta$ diffraction angle correspond to strong Bragg reflection. The incidence of these peaks is characteristic for zinc

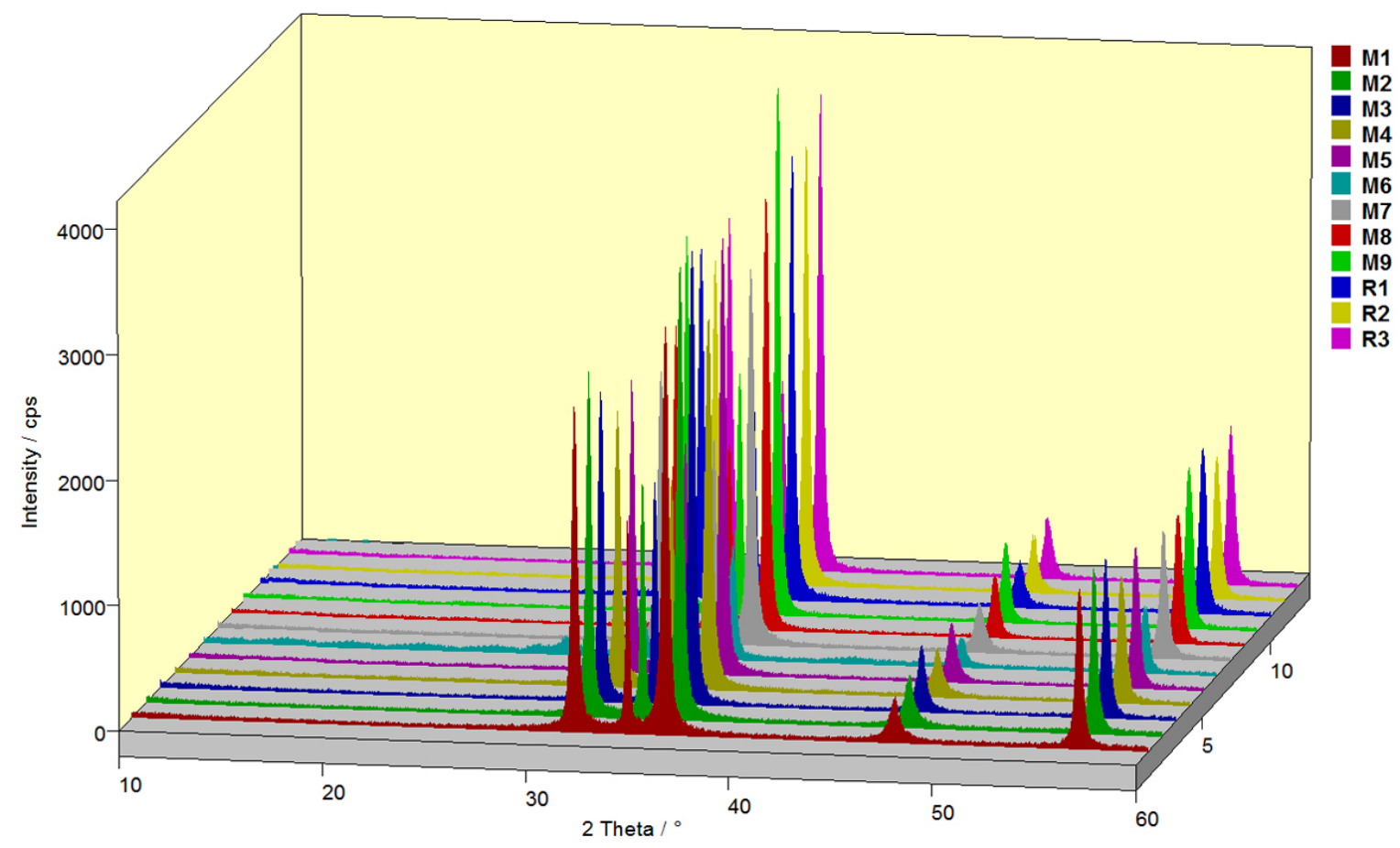

Fig. 2. XRD diffractogram of all samples 
oxide. ${ }^{19}$ Other reflections were not detected, which indicates high purity of samples. Peak intensity provides high crystallinity of products and their width reflects small size of crystallites. The size of crystallites was also calculated based on Scherrer equation:

$$
d=\frac{K \lambda}{\beta \cos \Theta},
$$

where

$\mathrm{K}$ - dimensionless shape factor $(\mathrm{K}=0.9)$

$\lambda-\mathrm{X}$-ray wavelength [nm]

$\beta$ - full width of peak at half maximum

$\Theta$ - Bragg angle

Values of calculated crystallites size are given in Tables 2 and 3. It should be noted that these size values concern the size of individual crystallites, which may consist the structure of nano- and microparticles that are characterized by larger sizes.

\section{3. Fourier Transform Infrared Spectroscopy}

Figure 3 presents typical FT-IR spectra of zinc oxide. During the FT-IR analysis a distinct characteristic absorption band at $440 \mathrm{~cm}^{-1}$ has been revealed. This band may be assigned to stretching vibrations of $\mathrm{Zn}-\mathrm{O}$. Other bands are derived from water present in products (stretching vibrations of $\mathrm{O}-\mathrm{H}$ at $3400 \mathrm{~cm}^{-1}$ ) and $\mathrm{Zn}-\mathrm{OH}$ at 880 $\mathrm{cm}^{-1} \cdot 20,21$

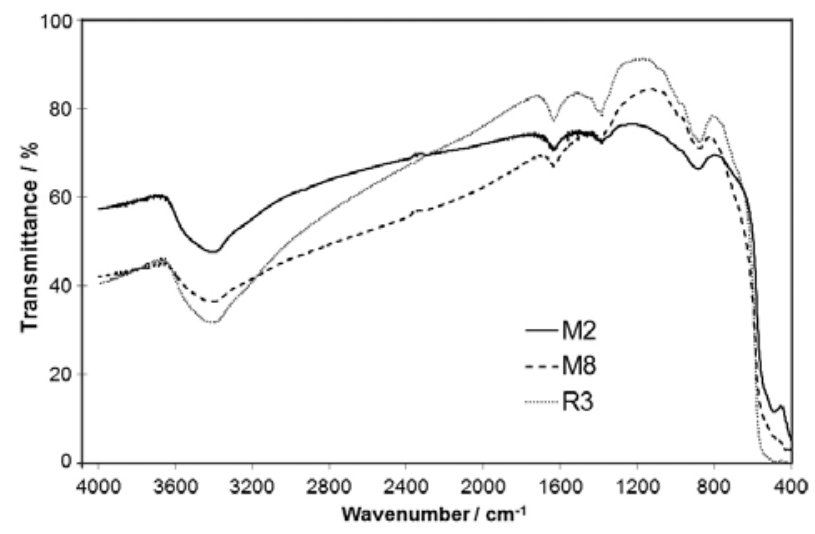

Fig. 3. FT-IR spectrum of obtained samples

\section{Conclusions}

It was possible to obtain zinc oxide particles both under microwave irradiation and in the laboratory pressure reactor. However, particles are distinguished by their varied shape and size. In general, they have lower average size in the case of obtaining them under microwave radiation. In addition, processes occur more efficiently when using microwave radiation. Thanks to the using of microwave irradiation, it is possible to efficiently transfer the heat in a short time throughout the whole volume of the reaction mixture, which greatly speeds up the processes completion.

\section{Acknowledgements}

This work is a part of the project Synthesis and Application of Innovative Nanomaterials with Antimicrobial Properties supported by National Centre for Research and Development under the Project LIDER/03/146/L3/11/NCBR/2012 for the period of 2012-2015.

\section{References}

1. P. H. C. Camargo, K. G. Satyanarayana, F. Wypych, Mater. Res. 2009, 12, 1-39. http://dx.doi.org/10.1590/S1516-14392009000100002

2. E. Roduner, Chem. Soc. Rev. 2006, 35, 583-592. http://dx.doi.org/10.1039/b502142c

3. C. Rao, G. Lulkarni, P. Thomas, P. Edwards, Chem. Eur. J. 2002, 8, 29-35. http://dx.doi.org/10.1002/1521-3765(20020104)8:1<28: :AID-CHEM28>3.0.CO;2-B

4. M. M. Mikhailov, V. V. Neshchimenko, S. He, C. Li, J. Spacecraft. Rockets. 2011, 48, 891-896. http://dx.doi.org/10.2514/1.42974

5. C. Li, V. V. Neshchimenko, M. M. Mikhailov, International Journal of Chemical, Nuclear, Metallurgical and Materials Engineering, 2014, 8, 388-392.

6. M. S. Spencer, Top. Catal. 1999, 8, 259-266. http://dx.doi.org/10.1023/A:1019181715731

7. W. A. Lazier, H. Adkins, J. Am. Chem. Soc. 1925, 47, 7191722. http://dx.doi.org/10.1021/ja01683a033

8. F. Weichelt, M. Beyer, R. Emmler, R. Flyunt, E. Beyer, M. Buchmeiser, Macromol. Symp. 2011, 301, 23-30. http://dx.doi.org/10.1002/masy.201150304

9. A. A. Keller, W. Vosti, H Wang, A. Lazareva, J. Nanopart. Res. 2014, 16, Article ID 2489.

10. T. G. Smijs, S. Pavel, Nanotechnol. Sci. Appl. 2011, 4, 95-112. http://dx.doi.org/10.2147/NSA.S19419

11. A. A. Tayel, W. F. El-Tras, S. Moussa, A. F. El-Baz, H. Mahrous, M. F. Salem, L. Brimer, J. Food Safety. 2011, 31, 211-218. http://dx.doi.org/10.1111/j.1745-4565.2010.00287.x

12. J. W. Wang, A. Cao, Y. Jiang, X. Zhang, J. H. Liu, Y. Liu, W. Hang, ACS Appl. Mater. Interfaces. 2014, 6, 2791-2798. http://dx.doi.org/10.1021/am4053317

13. R. Rajendran, C. Balakumar, H. A. M. Ahammed, S. Jayakumar, K. Vaideki, E. M. Rajesh, Int. J. Eng. Sci. Technol. 2010, 2, 202-208.

14. S. Kumar, P. Venkateswarlu, V. R. Rao, G. N. Rao, Int. Nano. Lett. 2013, 3, 30-35. 
http://dx.doi.org/10.1186/2228-5326-3-30

15. H. R. Nawaz, B. A. Solangi, B. Zehra, U. Nadeem, Can. J. Sci. Ind. Res. 2011, 2, 164-170.

16. S. Parashar, Process for the preparation of nano zinc oxide particles, US Patent Number 20,110,002,970 A1, date of patent January 6, 2011.

17. A. Kołodziejczak-Radzimska, T. Jesionowski, Materials. 2014, 7, 2833-2881.

http://dx.doi.org/10.3390/ma7042833

18. S. Ohara, T. Mousavand, M. Umetsu, S. Takami, T. Adschiri,
Solid State Ionics. 2004, 172, 261-264.

http://dx.doi.org/10.1016/j.ssi.2004.02.044

19. H. Kumar, R. Rani, Int. Lett. Chem. Phys. Astron. 2013, 14, 26-36.

http://dx.doi.org/10.18052/www.scipress.com/ILCPA.19.26

20. K. Nejati, Z. Rezvani, R. Pakizevand, Int. Nano Lett. 2011, 1, 75-81.

21. K. Sowri Babu, Ramachandra Reddy, C. Sujatha, K. Venugopal Reddy, A. N. Mallika, J. Adv. Ceram. 2013, 2, 260-265. http://dx.doi.org/10.1007/s40145-013-0069-6

\section{Povzetek}

$\mathrm{V}$ prispevku je predstavljena metoda priprave nano in mikrodelcev cinkovega oksida. ZnO smo pripravili pri povišani temperaturi in tlaku bodisi z uporabo mikrovalov ali uporabo ustreznih laboratorijskih reaktorjev. Mikrovalovi pospešijo potek reakcij, zato je metoda mirovalovne sinteze učinkovita v procesu priprave nanodelcev ZnO. Velikost delcev $\mathrm{ZnO}$ je redko presegla $500 \mathrm{~nm}$. 